\title{
The evolution and future of logistics and supply chain management
}

Ronald H. Ballou

Case Western Reserve University

\begin{abstract}
This article will be divided into three sections: past, present, and future. The past section will trace major events that created business logistics as it is practiced today. In particular, do the events portend the future of business logistics and supply chain management? The present section will attempt to summarize the state of business logistics. How business logistics relates to supply chain management will be addressed. The future section will make some predictions as to the issues that need to be addressed and the events that will likely take place in the near term.
\end{abstract}

Key words

Logistics, Supply Chain Management, Logistics history.

\section{A evolução e o futuro da logística e do gerenciamento da cadeia de suprimentos}

\begin{abstract}
Resumo
Este artigo se divide em três seções: passado, presente e futuro. A sessão sobre o passado traça os eventos mais importantes que criaram a logística empresarial como ela é praticada hoje. Em particular, tais eventos anunciavam o futuro da logística empresarial e do gerenciamento da cadeia de suprimentos? A sessão sobre o presente tenta resumir o estado da logística empresarial. Como a logística empresarial se relaciona com o gerenciamento da cadeia de suprimentos está abordado. A sessão futuro faz algumas previsões acerca das questões que precisam ser discutidas e dos eventos que provavelmente acontecerão em futuro próximo.
\end{abstract}

Palavras-chave

Logística, gerenciamento da cadeia de suprimentos, história da logística. 


\section{INTRODUCTION}

It has been my good fortune to experience the inception and growth of business logistics, and now supply chain management, as an area of academic study, research, and business practice. As a logistician, I will trace the evolution of thought in the field and make some predictions as to where the field may be headed. Much of what I have to say is based on my understanding of the events of the past as they occurred in the United States and what these events mean for the future. There is no documented historical record withstanding scientific scrutiny that can be used to validate what occurred and why. Conclusions in this article come from my impression of the events surrounding business logistics, their basis, and their meaning from the vantage point of one who has lived through the formation and growth of business logistics and who has been deeply involved in logistics education, research, and practice for more than 40 years.

This article will be divided into three sections: past, present, and future. The past section will trace major events that created business logistics as it is practiced today. In particular, do the events portend the future of business logistics and supply chain management? The present section will attempt to summarize the state of business logistics. How business logistics relates to supply chain management will be addressed. The future section will make some predictions as to the issues that need to be addressed and the events that will likely take place in the near term.

\section{THE PAST}

\section{The Backdrop}

Before the 1950s, logistics was thought of in military terms. It had to do with procurement, maintenance, and transportation of military facilities, materiel, and personnel. Although a few authors before this time began talking about trading one cost for another, such as transportation costs with inventory costs, and discussed the benefits to the firm of getting the right goods to the right place at the right time, the organization within the typical firm around the activities currently associated with logistics was fragmented. Figure 1 shows how a firm might have organized key activities at that time in terms of the responsibilities and objectives for marketing, finance, and production. This fragmentation led to conflicts among those responsible for logistics activities with the result that, from the firm's perspective, costs and customer service were sub-optimized. The reasons for this fragmentation were said to be:

- A lack of understanding of key cost tradeoffs

- The inertia of traditions and conventions

- Areas other than logistics were thought to be more important

- The organization may have been in an evolutionary state

Later, it was learned that there are benefits to eliminating the fragmentation such that (1) it encourages important tradeoffs to occur that can lower total costs, (2) it focuses on an important, defined area by top management, and (3) it sets the structure within which control can take place.

Figure 1: Logistics Activity Fragmentation in Early Firms.

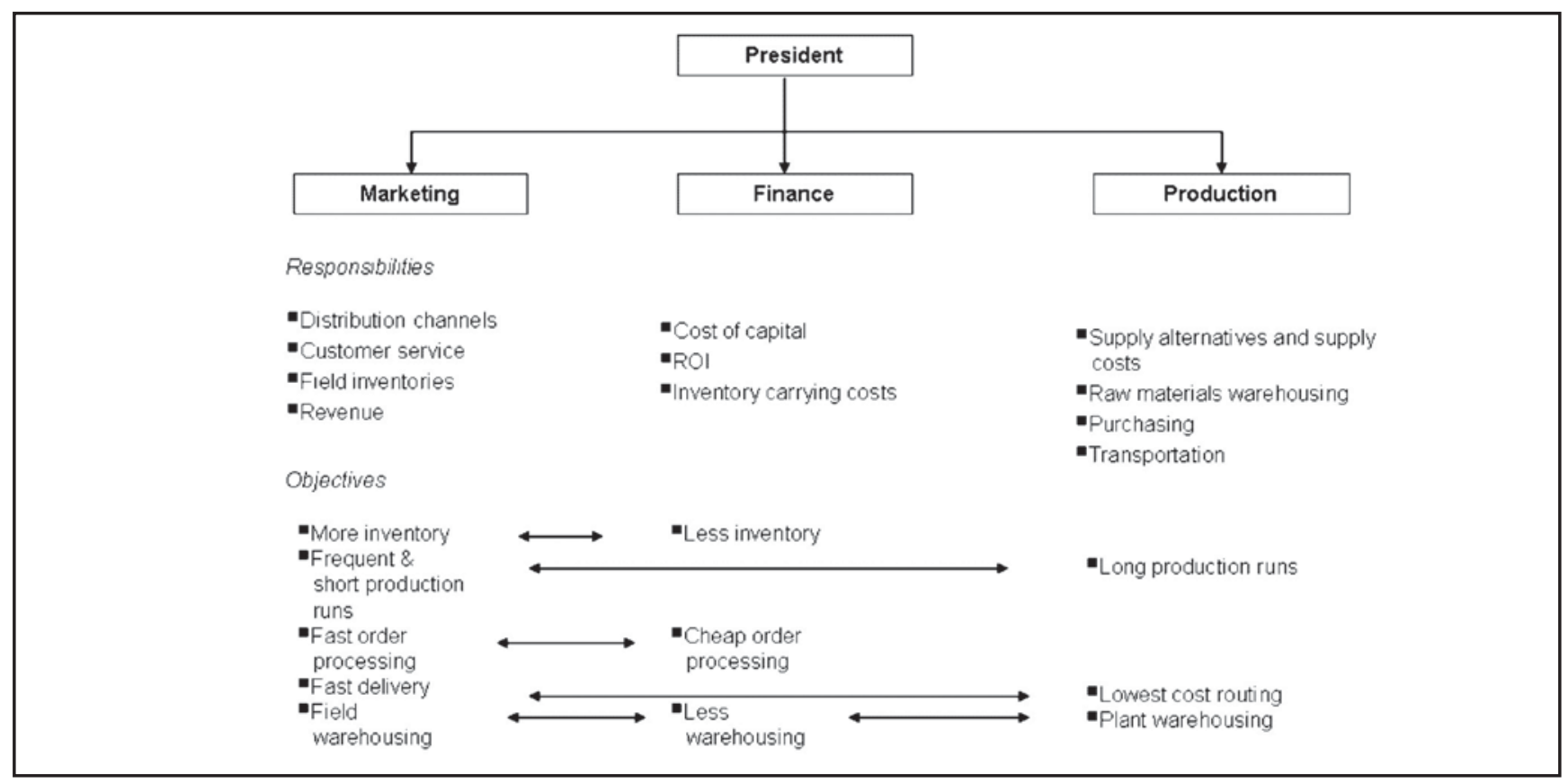


Educational courses and programs at the time were not focused on logistics or distribution. They were mainly related to individual activities such as transportation and purchasing. There was little attempt to integrate and balance the activities, later to be known as logistics activities, that were in cost and/or service conflict. Hence, there was not much of an opportunity for managers to learn about the broader concepts of logistics.

Physical distribution begins to emerge as an area of study and practice, which is the coordination of more than one activity associated with physically supplying product to the marketplace. LaLonde and Dawson (LaLonde and Dawson, 1969) trace the early history and note that Arch Shaw in 1912 began to see the two sides of marketing, where one deals with demand creation (promotion) and the other with physical supply, and Fred Clark in 1922 identified the nature of physical distribution and pointed out how it was different from the demand-creating nature of marketing. Marketing as a discipline was creating interest at this time and scholars did include distribution as a primary activity in the marketing mix, however, distribution seemed to be defined more in terms of transaction channel activities than physical distribution ones. Paul Converse (Converse, 1954), a noted marketing professor, said in 1954 that businesses had been paying a great deal more attention to buying and selling than to physical distribution.

In retrospect, research that would play a pivotal role in laying the foundations for physical distribution was a study by Lewis et al. (Lewis et al., 1956). This study for the airline industry asked how it might better compete in hauling freight when its costs were significantly higher than other forms of transportation. The study pointed out that it is necessary to view shipping from a total cost perspective and not from just a transportation cost one. That is, although air freight cost may be high, air freight's faster and more reliable service can lead to lower inventory carrying costs on both ends of the shipment. This was an expression of the total cost concept that was to underpin much of writing and teaching to follow in the $1960 \mathrm{~s}$.

The first college course (Michigan State University) and textbook (Smykay et al., 1961) appeared around 1960. Within the context of the total cost approach, activities such as transportation, inventory control, warehousing, and facility location were discussed. The emphasis was on a firm's outbound movement of goods and dealt little with inbound movements. In 1964, the scope of physical distribution was expanded (Heskett et al., 1964) to include physical supply and was called business logistics. Using the descriptive name of business logistics was not only an attempt to distinguish the name from military logistics but to focus on logistics activities that took place within the business firm. Purchasing was not generally considered nor was production. On the other hand, there was a similar movement by those interested in the purchasing activity. Whereas purchasing was initially considered a buying activity, there were efforts to expand the scope to include many of the activities familiar to physical distribution but associated with the inbound side of the firm. This expanded scope was embodied in such names as procurement and materials management.

\section{Emergence of Physical Distribution and Logistics}

The study and practice of physical distribution and logistics emerged in the 1960s and 1970s. Logistics costs were high. On a national level, it was estimated that logistics cost in the U.S. accounted for 15 percent of the gross national product (Heskett et al., 1973). Similarly, physical distribution costs of other nations were found to be high as well. For example, in the United Kingdom, they were 16 percent of sales (Murphy, 1972), in Japan they were 26.5 percent of sales (Kobayashi, 1973), in Australia they were 14.1 percent of sales (Stephenson, 1975), and as of 1991 in China they were 24 percent of GDP (Wang, 2006). On an individual firm level, they could be as high as 32 percent of sales (LaLonde and Zinszer, 1976). The recognition of these high costs led one writer to declare physical distribution as one of "the most sadly neglected, most promising areas of American business" (Drucker, 1962). With marketing and production being relatively mature areas of analysis, physical distribution and logistics were the next obvious areas for managerial attention.

Physical distribution with its outbound orientation was first to emerge, since it represents about two thirds of logistics costs and it was considered a component of the marketing mix (product, place or physical distribution, promotion, and price) of essential elements. Business logistics, with its broader scope that includes inbound movement, was soon to follow. It is useful to look at what was envisioned by early proponents of the areas to see the fit with current views and to give some idea of future directions.

When comparing the early vision of physical distribution and logistics with the current one for supply chain management, there is little difference. For example, the definition in 1962 offered by Smykay et al. (Smykay et al., 1962) was:

"Physical distribution can be broadly defined as that area of business management responsible for the movement of raw materials and finished products and the development of movement systems."

Although physical distribution is usually associated with outbound product movements from a firm, this definition indicates a broader concept that includes both inbound and 
outbound movements. Heskett et al. (Heskett et al., 1964) described business logistics in terms of both physical supply and physical distribution, but they also recognized that logistics takes place throughout the supply channel, from producer to end consumer. Figure 2 shows the multiple echelons of a supply channel for flour, and Heskett et al. suggested that there needs to be coordination of the product flows throughout the entire channel. These concepts are similar to what is currently described as supply chain management and, at that time, physical distribution and logistics were somewhat synonymous terms. Although these early definitions suggest a broad scope for physical distribution and logistics, the focus was on coordinating among the activities within the function, with little emphasis on coordinating among the other functions within the firm or among external channel members. This limited application of a much broader scope probably had to do with technological limitations of information systems at the time and the difficultly of managing across areas of responsibility.

Most notably missing from early definitions was a direct reference to purchasing and production. Although they may have been implied, they were rarely treated in logistics education or practice.

As previously indicated, marketing considered physical distribution to be a part of the marketing mix, however, the greatest interest seemed to be in transactional channels while physical distribution was given short shrift. On the other hand, production claimed logistics activities as part of the product function. According to Timms and Pohlen (Timms and Pohlen, 1970):

"...one can conceive of production as a function directly concerned with providing form, time and place utilities in the product."

Time and place utilities are usually referred to as physical distribution or logistics activities. Although marketing and production were established functions within business, and they laid claim to physical distribution, but their lack of attention led physical distribution (logistics) to be developed as a separate entity and as a new function within a firm's organizational structure.

In these early years, not only did scholars and practitioners struggle with a definition for the field, they could not agree on a title. Some of the familiar ones were:

- Distribution

- Physical distribution

- Logistics

- Business logistics

- Integrated logistics

- Materials management

- Value chains

- Rhocrematics, a Greek term referring to the management of material flows.

Figure 2: Multiple Echelons of a Logistics Channel for Flour Supply and Delivery.

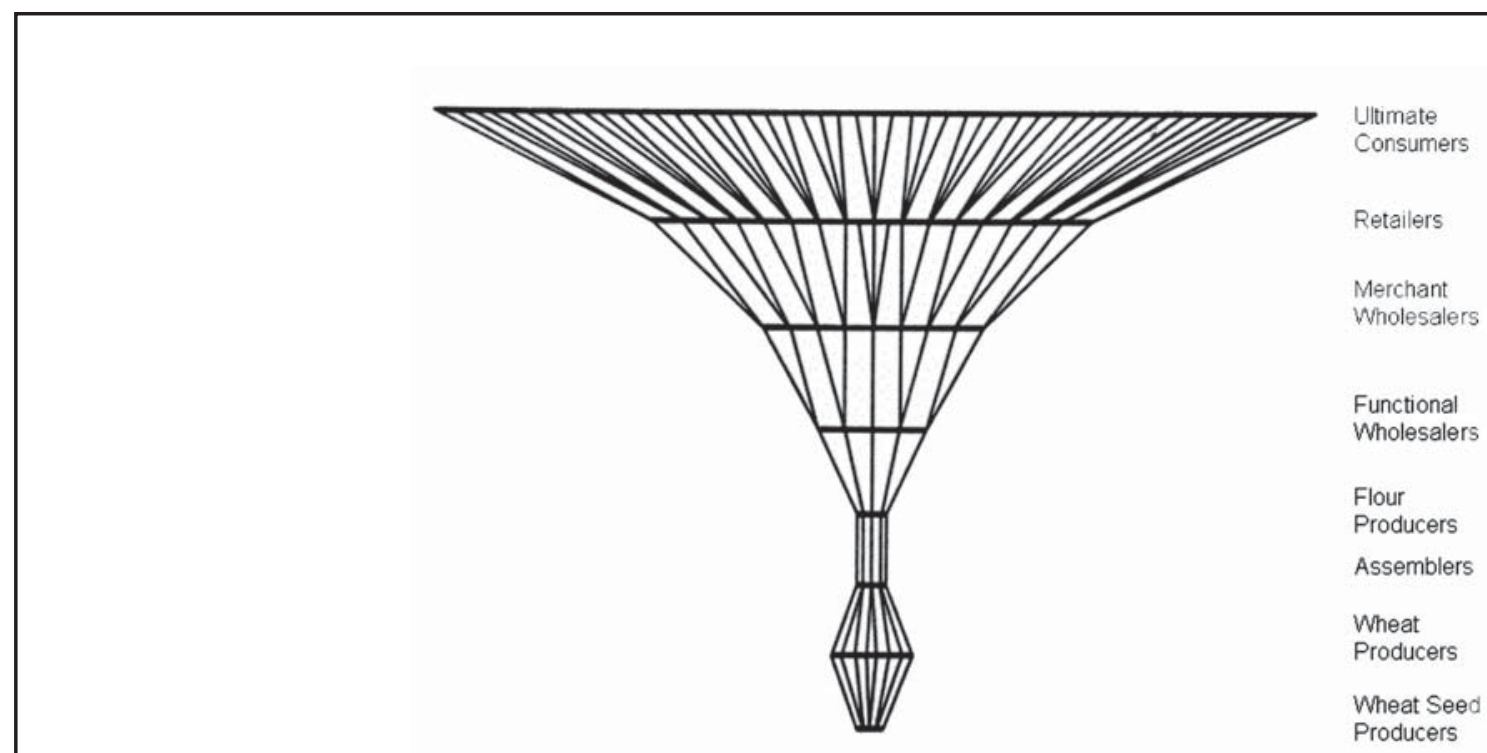

Source: Heskett, J. L., Robert M. Ivie, and Nicholas A. Glaskowsky, Jr. (1964), Business Logistics: Management of Physical Supply and Distribution (New York: Ronald Press), p. 25. 


\section{Conclusions from the PAST}

There are several lessons to be learned from the past. First, physical distribution and logistics were envisioned to have broad responsibilities for managing activities associated with product flow from the points of raw material acquisition to the end consumer. Although the scope of the field was extensive, actual management practice was generally limited to coordination of activities within the logistics function or among those activities associated with product flow. Boundary-spanning management was embraced but little practiced.

Second, the total cost concept served as the basis for managing certain activities collectively. Activities such as transportation and inventory control were collectively managed because they were in cost conflict. All those activities associated with product flow and displaying this cost tradeoff characteristic were considered a part of the new field of physical distribution or logistics.

Third, physical distribution and logistics were embraced by both marketing and production areas, but they gave little attention to issues of product flow. As a result, physical distribution and logistics began to develop as an independent function within business. This action was spurred by the recognition that logistics costs were high and that there was an unrealized opportunity to reduce them.

Fourth, among the areas of purchasing, production, and physical distribution, there was little coordination, even though they had a direct effect on product flow management. This coordination was to become a major theme in later years.

\section{THE PRESENT}

A new name emerges: Supply Chain Management (SCM). This name is taking the logistics area by storm since so many in various business fields seem to embrace it and see activities of their areas imbedded in it. The origin of the name seems a mystery and exactly what supply chain management is, compared with physical distribution and logistics, is being debated. Some are saying that it is a fulfillment of the activity integration promise implied in early definitions while others think it is a new and bold concept. Those believing that supply chain management is evolutionary construct a diagram of the type shown in Figure 3. The claim is that supply chain management is not new and they recognize that the logistics pioneers had many of the ideas promoted by current supply chain enthusiasts. For example, note what Heskett et al. said in 1964 (Heskett et al., 1964) with reference to the flour tree of Figure 2:

"Each transfer of goods from one business entity to the next requires the coordination of demand and supply between many different institutions in the channel, from the original grower of wheat seed to the ultimate consumer of flour."

Specifically, note that they refer to the entire supply channel and suggest that coordination is needed throughout the channel. These are ideas that form the basis for supply chain management as practiced today.

Figure 3: Evolution of Supply Chain Management.

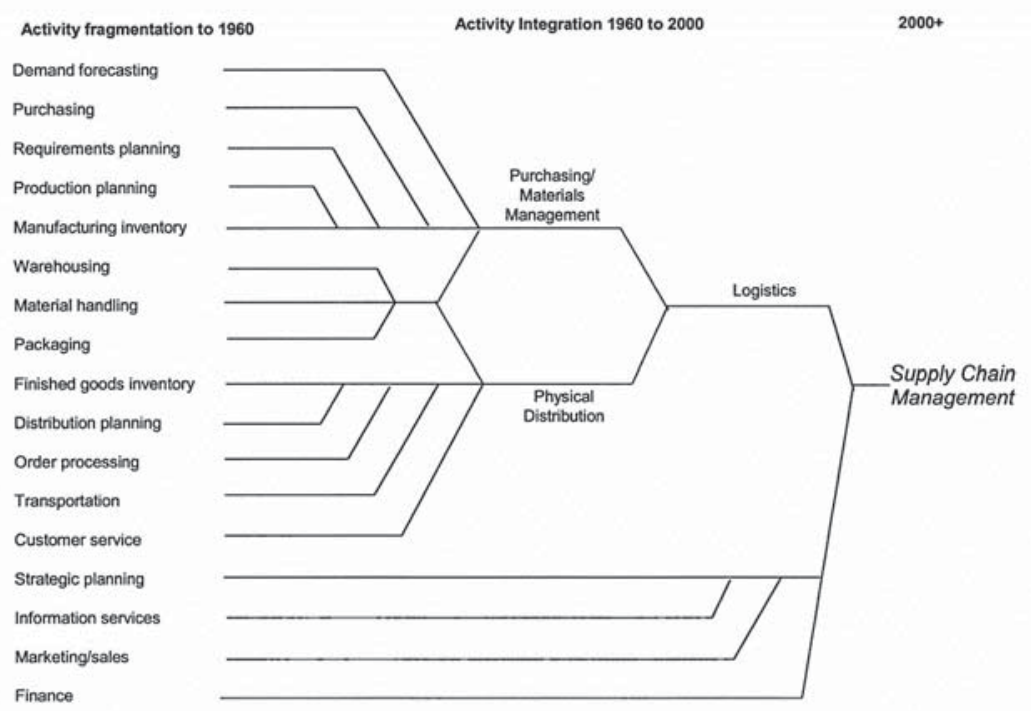


Given 40 years of background with a broad concept for logistics, what exactly is supply chain management to its proponents? There has been an attempt to distinguish logistics from supply chain management, declaring logistics to be a subset of supply chain management. Recently, the Council of Supply Chain Management Professionals (CSCMP), which is the premier organization of supply chain practitioners, researchers, and academics, has defined supply chain management as:

Supply Chain Management encompasses the planning and management of all activities involved in sourcing and procurement, conversion, and all Logistics Management activities. Importantly, it also includes coordination and collaboration with channel partners, which can be suppliers, intermediaries, third-party service providers, and customers. In essence, Supply Chain Management integrates supply and demand management within and across companies.

Whereas, CSCMP defines logistics to be:

Logistics Management is that part of SCM that plans, implements, and controls the efficient forward and reverse flow and storage of goods, services, and related information between the point of origin and point of consumption in order to meet customer requirements.

In these two definitions, first note that procurement (i.e., purchasing) and conversion (i.e., production) are now explicitly included in the scope of managing material flows. Second, emphasis is placed on coordination, collaboration and relationship building among channel members that are missing from logistics management. Put another way, supply chain management can be viewed as having three dimensions. These are activity and process administration, interfunctional coordination, and interorganizational coordination. Activity and process administration is much of what logistics has been doing. That is, managing activities such as transportation, inventories, warehousing, and order processing that are within the responsibility of the logistics function. Interfunctional coordination refers to collaborating and building relationships with other functional areas in the same firm, such as with marketing and finance. Interorganizational coordination has to do with collaborating and coordinating product flows among channel members, i.e., those companies that are not owned or operated by the immediate firm. Therefore, SCM is viewed as managing product flows across multiple enterprises (see Figure 4) whereas logistics is seen as managing the product flow activities just within the firm. This is a deviation from the view that the early visionaries had for logistics.

A contemporary view of supply chain management is to think of it as managing a set of processes, where a process is a group of activities relevant to achieving a defined objective, such as filling orders. The Amercan Marketing Association in 2004 defined marketing in terms of processes:

"Marketing is an organizational function and a set of processes for creating, communicating and delivering

Figure 4: The Multiple Enterprises of the Supply Chain

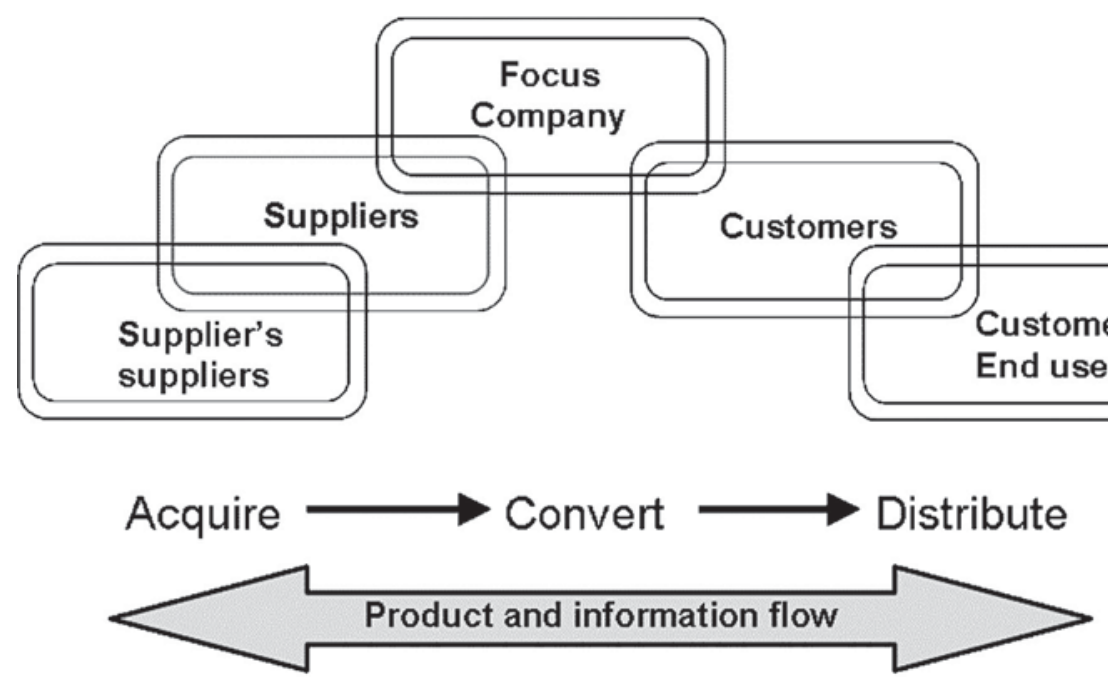


value to customers and for managing customer relationships in ways that benefit the organization and its stakeholders."

Based on collaboration with industry leaders, Lambert et al. (Lambert et al., 1998) defined eight key subprocesses for supply chain management. These are (1) customer relationship management, (2) customer service management, (3) demand management, (4) order fulfillment, (5) manufacturing flow management, (6) supplier relationship management, (7) product development and commercialization, and (8) returns management. Taken together, they represent supply chain management in its entirety. These processes are to be coordinated through collaboration and relationship management throughout the various echelons of the supply channel, from initial suppliers to end consumers.

Although there is much talk about the benefits of collaboration among channel members and expanding the scope of product flow management to include the entire supply chain channel, to what extent is the theoretical scope of supply chain management actually practiced? Fawcett and Magnan (Fawcett and Magnan, 2002) conducted a survey to find out. Their results are captured in Figure 5. In reality, few firms reach the potential of theoretical integration. About one-half of the firms surveyed are working toward integration within the walls of their own firms. Whether this interfunctional integration is attributed to the implementation of large software systems such as SAP rather than to actual collaboration and compromise is not clear. Approximately one third of the firms focus their integration efforts on their first-tier suppliers. Beyond that, there is little attempt at integration. This is probably due to the inherent difficulties of achieving effective collaboration and to the limitations brought about by competition, such as the reluctance to share proprietary information.

\section{Conclusions from the PRESENT}

A number of conclusions can be drawn from observing product flow management at the present time. Clearly, excitement and focus are directed toward supply chain management. First, we can say the supply chain management is concerned with realizing the opportunities from integrated management of product flow processes across functions and between channel members. Although the idea is potent and the benefits obvious, the notion of lowering costs by including more of a system in decision making is not new. It was at least embodied in the systems approach promoted by operations researchers in the 1940s and 1950s.

Figure 5: Scope of Supply Chain Management as Currently Practiced.

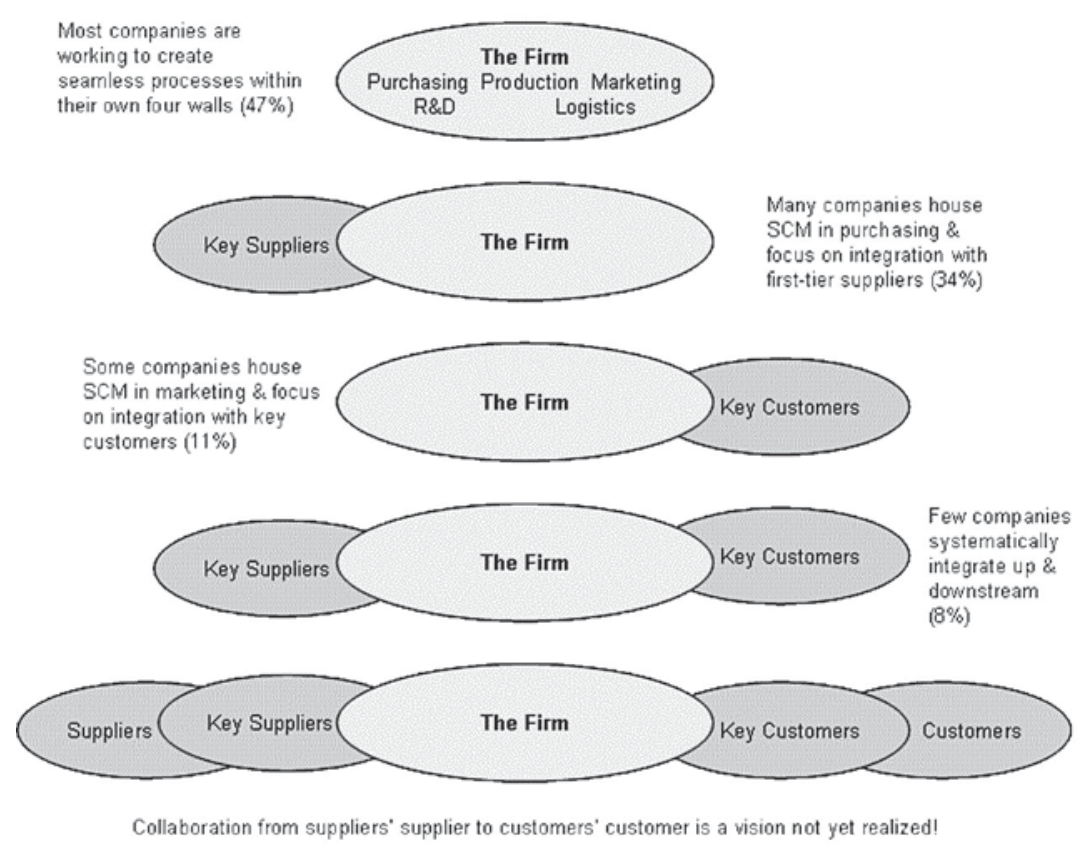

Source: Stanley E. Fawcett and Gregory M. Magnan (2002), "The Rhetoric and Reality of Supply Chain Integration," International Journal of Physical Distribution \& Logistics Management, Vol. 32, No. 5, pp. 339-361. 
Second, logistics is now being viewed as a subset of supply chain management. The scope of logistics is being limited to the boundaries of the function within a firm and is primarily concerned with activity administration, which was not the early view. Interfunctional and interorganizational management seem to be within the purview of supply chain management rather than logistics. Logistics, as an identifying name, supersedes physical distribution.

Third, purchasing and production are now included within the scope of supply chain management. As a result, SCM is responsible for 70 to $80 \%$ of the cost of sales for many firms.

Fourth, so many functional areas of the firm are embracing supply chain management that it is in danger of becoming so broad that it loses its identity and focus. Some limitations and organizational subdividing may occur.

Fifth, although supply chain management promotes coordination, integration, relationship building, and collaboration throughout the entire supply channel, SCM currently takes place to a very limited degree. The most likely place for SCM to occur is between the firm and its firsttier suppliers. Currently, SCM is practiced as logistics and not the broad, theoretical scope envisioned for it. Perhaps managers will begin to practice SCM when its benefits are better documented and measured, and the techniques and tools needed to achieve the benefits are refined.

\section{THE FUTURE}

Understanding the past and observing the present allows an extrapolation to what might be in store for logistics/SCM in the future. The trend toward increased globalization, free trade, and outsourcing all contribute to a continued and growing interest in logistics/SCM. According to a McKinsey \& Company study,

"...by the year $2020,80 \%$ of the goods in the world will be manufactured in a country different from where they are consumed compared with $20 \%$ now."

There will be a tremendous shift in the movement and consumption of goods, all of which will require ever better management of the associated supply chain processes.

There will be a shift in strategy. In the past, the focus of logistics/SCM has been on efficiency. As Peter Drucker (Drucker, 1962) put it, physical distribution is:

"The last frontier of cost economies."

The contemporary view is that SCM is a new frontier for demand generation - a competitive weapon. Both views will be important, but the new emphasis will be on designing and operating the supply chain to enhance the revenues of the firm in such a way as to maximize contribution to profit. This view replaces the often-used strategic objective of minimizing supply chain costs, subject to meeting given customer service requirements, and it will elevate SCM in the eyes of top management. A new objective will emerge to capture revenue enhancement effects, which is called ROSCA. The objective of ROSCA is to maximize return on supply chain assets. It is defined as:

ROSCA $=\frac{\text { Revenue }- \text { Costs }}{\text { Assets }}$

where Revenue refers to the supply chain's contribution to the sales of the firm, Costs refers to the expenses incurred in supply chain processes, and Assets refers to the investment made in facilities and equipment to support the supply chain processes. Managers have long calculated the ratio of costs to assets, or return on investment, as a measure for judging the value of strategic alternatives. When investments are made to improve customer service, the traditional returnon-investment understates the benefits of the strategy by omitting its revenue enhancement possibilities. While ROSCA is an improved measure, estimating revenue effects remains difficult and is a topic for much needed research. A summary of some of the currently available revenueestimating methods is offered by Ballou (Ballou, 2006).

Collaboration and coordination will be the keys to achieving the benefits of supply chain management. When both parties in a supply chain relationship win equally due to their cooperative actions in the supply channel, the benefits are likely to be realized and the relationship remains intact. In too many cases, this does not occur and there is a dilemma that must be resolved. The conflict can be illustrated with a simple example.

Example. Suppose that a supply chain is composed of two members - a buyer and a seller. The buyer annually uses $D=10,000$ units of purchased component. The buyer incurs an ordering cost of $S_{b}=\$ 100$ when buying the component from an upstream supplier. The buyer's holding cost for one item is $H_{b}=\$ 10$ per year. Based on the EOQ formula for optimizing order quantity, the buyer prefers to place orders of the size:

$$
Q_{b}^{*}=\sqrt{\frac{2 D S_{b}}{H_{b}}}=\sqrt{\frac{2(10,000)(100)}{10}}=447 \text { units }
$$

On the other hand, the seller produces the component to order whenever a purchase order is received from the buyer. The setup cost for producing a batch is $S_{s}=\$ 300$ and the total annual setup cost $\left(C_{s}\right)$ depends on the buyer 's quantity: 
$C_{s}=\$ 300 D / Q_{b}$. Obviously, the more frequently the buyer places purchase orders, the more setup costs are incurred by the seller.

If the channel is managed as a single entity, the order quantity to minimize channel cost is:

$$
Q_{c}^{*}=\sqrt{\frac{2 D\left(S_{b}+S_{s}\right)}{H_{b}}}=\sqrt{\frac{2(10,000)(100+300)}{10}}=894 \text { units }
$$

The cost curves for the channel members and for the supply chain are shown in Figure 6. Note the optimal order quantities for the buyer and for the supply chain. The supply chain cost is the combined costs of the buyer and seller. Seller wishes the largest order size possible. Because there is a difference between the order quantities that each member and the channel prefer, there is said to be a cost conflict. As shown in Table 1, if the buyer dictates the purchase order size, the annual channel cost will be $\$ 11,183$. On the other hand, if the order quantity is set at that which will minimize the combined cost of the members, the annual channel cost can be reduced to $\$ 8,945$, a potential cost reduction of $\$ 11,183-8,995=\$ 2,238$. In order to realize the cost reduction, the buyer must agree to order 894 units at a time, which will increase his direct annual cost from $\$ 4,472$ to $\$ 5,589$. Since the benefits of this larger order size "pool" with the seller, the seller must share some of his gains $(\$ 6,711-3,356=\$ 3,355)$ with the buyer in an amount equal to or greater than $\$ 5,589-4,472=\$ 1,117$. If less than this, the coalition is not likely to hold together and the buyer will revert to his preferred purchase order quantity and the coalition is likely to dissolve. A key question then is: What mechanisms can be used for sharing the system-wide benefits so that both members benefit and have the incentive to continue their cooperation?

A number of both formal and informal mechanisms have been identified whereby the benefits of channel cooperation might equitably be shared among the members (see Ballou et al., 2000). Among the formal mechanisms are price adjustments and order quantity minimums. The seller might offer price discounts as an incentive for the buyer to order in quantities that lower the seller's cost but also lower the buyer's cost through the price reduction. The seller might also set order-size minimums to encourage more desirable order quantities.

Informal mechanisms do not distribute funds directly among channel members, but they offer incentives indirectly to encourage cooperation. These have to do with power and trust. Large firms may use coercive power to force other

Table 1: Cost Summary for Supply Chain Example*.

\begin{tabular}{|c|c|c|}
\hline & $\begin{array}{r}\text { Buyer's } \\
\text { optimal } \\
Q=447 \text { units }\end{array}$ & $\begin{array}{r}\text { Supply } \\
\text { Chain's } \\
\text { optimal } \\
Q=894 \text { units }\end{array}$ \\
\hline Sellera & $\$ 6,711$ & $\$ 3,356$ \\
\hline Buyerb & 4,472 & 5,589 \\
\hline Supply Chain ${ }^{c}$ & $\$ 11,183$ & $\$ 8,945$ \\
\hline $\begin{array}{l}{ }^{\mathrm{a}} T C_{s}=S_{s} D / Q_{s} \\
{ }^{\mathrm{b}} T C_{b}=S_{b} D / Q_{b} \\
{ }^{\mathrm{c}} T C_{c}=\left[S_{s}+S_{b}\right]\end{array}$ & $\begin{array}{l}1 / 2 \\
+H_{b} Q / 2\end{array}$ & \\
\hline
\end{tabular}

*Bold numbers show buyer's and supply chain's preferred cost levels.

Figure 6: Costs in the Supply Channel.

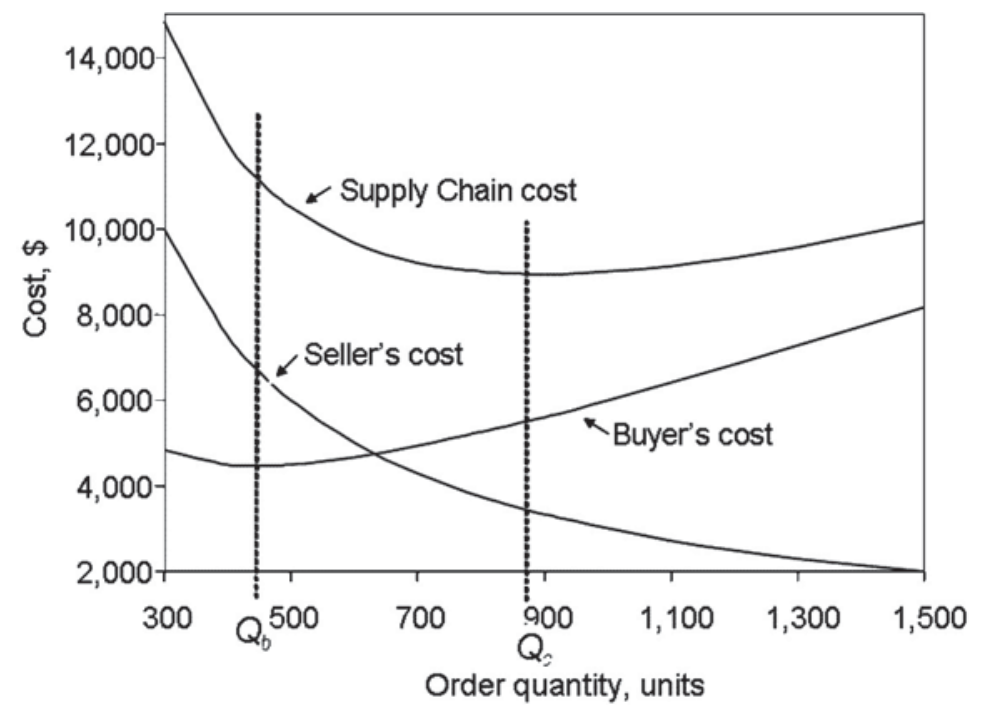


channel members to comply with their wishes. Reward and referent power are less straight forward and offer benefits to cooperation through such mechanisms as training or use of a valued name, such as Intel Inside. Trust has to do with sharing information among members so that they can be in a better position to make decisions benefiting all channel members in the coalition.

Collaboration among supply chain members is at the heart of supply chain management and will be the key to its future success. The essence of channel collaboration has several identifiable features. First, it is about managing a supply channel of vertically-related but legally separate firms. Second, it represents an untapped opportunity because channel members often work at cross purposes. Third, cooperation and trust are the keys to realizing the benefits from collaboration. Fourth, the benefits may "pool' with one or a few channel members, thus creating the need for sharing the benefits. Fifth, redistributing the benefits requires (1) metrics to identify and measure potential benefits, (2) information sharing among the members to build trust, and (3) sharing methods for a fair benefits distribution. To summarize, channel collaboration will require (1) information sharing and a spirit of cooperation, (2) a boundary-spanning information system (3) inter-organizational metrics, (4) a means for benefits identification, and (5) ways for sharing the spoils of cooperation. A particular need is for an information system that is inter-organizational in scope and is directed toward providing relevant information so that channel members can "see" the opportunities for supply chain improvement and can track the flow of the benefits from cooperation.

\section{Conclusions for the FUTURE}

Without a doubt, logistics and supply chain management will continue to grow in importance as companies continue to pursue outsourcing, expand their international operations, and do business in a global economic environment. Whatever the field is called that manages product flows, which at the moment is supply chain management, the trend is set. Here are the major challenges likely to confront SCM in the near future.

A revenue generation strategy for the supply chain will be as important as a cost reduction one. There will be increased attempts to view supply chain strategies as a way of generating the revenues of the firm much in the same way it views product mix, advertising, and price as elements of its marketing strategy. Designing the supply chain processes that result in a level of logistics customer service is the basis for a supply chain strategy, since logistics customer service is related to revenue. The cost of the processes will be managed to maximize ROSCA associated with the strategy.

Boundary-spanning benefits of SCM may be easy to identify but will be hard to realize. Taking a broader, systems approach to supply chain decisions can obviously identify greater cost savings and/or customer service improvements than a narrower, individual firm perspective. Given cost and revenue information of the channel members, the potential benefits can be calculated and the best course of action identified. Since the benefits often accumulate ("pool") with one or a few of the members, the decision-making process is inherently unstable. That is, the individual channel members will revert to actions that maximize their self interest when, in their view, the benefits of cooperation and compromise are not fairly shared. Lack of boundary-spanning information, trust, and communication are at the core of realizing supply chain benefits, and these elements are difficult for logisticians who must manage beyond the firm's legal borders and their direct sphere of responsibility.

Coordination and collaboration, along with trust, are the most important elements to realizing boundary-spanning opportunities. When the supply channel is composed of multiple and legally separate members, realizing the opportunities afforded by acting in concert requires a collaborative effort. Relationships are forged that are built on trust. Proprietary information often must be shared, and trust must precede the sharing. Collaboration, coordination, and trust are key elements in SCM, but they often involve skills that logisticians have not had to exercise to the same degree as when managing product flows strictly within the boundaries of their own firms. New skills are required.

Information sharing among channel members is likely to continue with advancing technology and may be called coordination, compromise, and cooperation. Improvements in quantity, quality, and dissemination of information throughout the supply chain are primary reasons for considering boundary-spanning management. Too often information sharing masks as channel partner collaboration and substitutes for true compromise. SCM is more complicated than swapping data between companies and among the various functional areas within a firm. In many cases, the channel partners are required to compromise their positions regarding supply chain decisions, which is the most difficult aspect of SCM. Future research should be directed to help managers deal specifically with SCM issues to achieve compromise.

Boundary-spanning metrics will be needed to identify supply chain benefits and track their location in the supply channel. There is a weakness in the accounting systems needed to operate in a supply chain environment. Current corporate accounting systems do little to track costs beyond a firm's legal borders. It is difficult for one channel partner to see the costs of another that are associated with a coordinating action. Trust, an essential ingredient of collaboration, may suffer. If the opportunities of SCM are to be exploited, a 
boundary-spanning accounting system is needed that assists channel members in seeing the economic consequences of their coordinated actions and identifies where the benefits are going. Such a system will help identify the magnitude of supply chain benefits as well as the extent to which benefits' sharing is needed.

Methods of benefits sharing need better definition and refinement. Once the benefits of supply chain cooperation are identified, actions need to be taken to share the benefits and keep the coalition operating in a manner to continue producing these benefits. Some methods, both formal and informal, were previously noted; however, it is not clear which is most effective and under which circumstances. Research will help to clarify the best choices and how they can be applied.

Supply chain relationships are not inherently steady-state, so examples of good supply chain coordination among a few firms will be selective and short term. Because coalitions are fragile and the members may easily return to the state of their self interest when trust is broken, information is incomplete or inaccurate, and the sharing of benefits is perceived to be or is actually unfair, there are likely to be few examples of real supply chain cooperation spanning many echelons in the channel. Therefore, we can expect only isolated examples where extensive channel cooperation has occurred. There will be some selected examples among a pair of channel partners, which is most likely to be between a firm and its immediate suppler. Considering the difficulty of holding relationships together, the lack of a good boundary-spanning accounting system with appropriate metrics, and with little managerial training in supply chain relationship building, it will be many years before the promises of SCM are realized.

Logistics curricula transforming to a supply chain curricula should be expanded to include the subjects of relationship and trust building. On an educational level, teaching supply chain management will require additional topics not now included in a typical logistics curriculum. Boundary-spanning management is based on relationship building, collaboration, compromise, and coordination across legally separate firms, but these dimensions have not historically been a central part of logistics education. Logistics educators typically received their training in marketing, operations, and quantitative methods. In addition, skills in organizational behavior and psychology will be needed. These skill sets are quite opposite, which suggests that current educators are poorly equipped to deal with the new managerial dimensions required of a supply chain environment. Yet, these additional dimensions should be brought into logistics education if the promises of supply chain management are to be fulfilled.

Operations, purchasing, and logistics will merge organizationally, probably under the supply chain banner. The broad scope of supply chain management will have an impact on organization within a firm. Whereas logistics may have been practiced with a limited scope, SCM requires management across many functions within the firm. In order to achieve coordination as suggested in SCM, it may be necessary for firms to reorganize. For those firms seeking a formalized arrangement, the organizational structure is likely to evolve to that shown in Figure 7. Purchasing and production were often put on a par with marketing and finance, but in the future, these functions, as well as logistics, will be under the guidance of the supply chain manager. For those firms wishing to achieve good coordination of product flows, they may opt for a less formal arrangement, such as a supply chain liaison placed at the top of the organization who has responsibility for coordinating supply chain actions across the various functions within the firm. To coordinate among supply chain channel members, committees composed of channel members will emerge since formal organizational structures across legally separate firms are not likely to occur.

Figure 7: A Future Organization for Supply Chain Management.

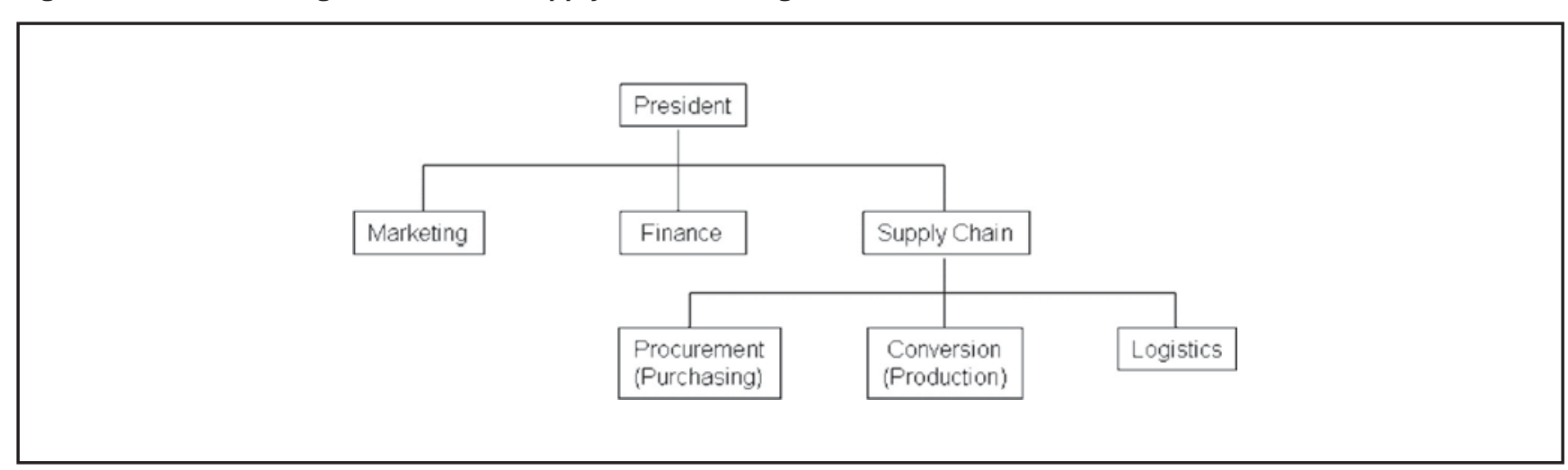




\section{REFLECTION}

Forty-five years have seen physical distribution/business logistics/supply chain management go from individually managed activities that are product-flow related to an integrated set of processes managed across multiple echelons of a product supply chain. SCM has never been more important to business than it is currently, or will be in the near future. It has the potential of production/engineering in the industrial revolution and marketing of the 1920s and 1930s when each of these gained prominence in business. SCM often is the basis for a firm's competitive strategy, which is driven by increased outsourcing, expanding global operations, and heightened need for logistics customer service. Not only has managing supply chain costs become more important, as these costs are used in tradeoff with production costs, but supply chain strategy is increasingly viewed as a source for contributing to the revenues of the firm.

Key challenges for the future will be to better estimate the revenue contributions from the customer service levels generated by the supply chain and effectively managing the scope of the supply channel as envisioned in supply chain management. Because of the difficulty of estimation, too little attention has been given to the revenue contribution that the supply chain can make to the overall sales of the firm. It is an area of much needed research.

Proponents of SCM are making bold statements about the benefits of boundary-spanning management but offer little as to how these benefits can actually be realized. Businesses have yet to progress very far with boundary-spanning management, probably because the tools and skills are not well developed. If the promises of SCM are to be realized, an interorganizational accounting system, appropriate metrics for defining and tracking shared benefits, and acceptable methods for benefits sharing will need to be developed. Also, supply chain managers will need training in collaborative techniques, relationship and trust building, and skills for compromise. These will require major efforts by the academic, research, and business communities, but the rewards can be substantial.

\section{- References}

Ballou, Ronald H. (2006). "Revenue Estimation for Logistics Customer Service Offerings," The International Journal of Logistics Management. v. 17 , n. 1, p. 21-37.

Ballou, Ronald H.; Stephen Gilbert, and Ashok Mukerjee (2000), "New Managerial Challenges from Supply Chain Opportunities" Industrial Marketing Management, v. 29. n. 1, p. 7-18.

Converse, Paul D. (1954), "The Other Half of Marketing," Twenty-sixth Boston Conference on Distribution (Boston: Boston Trade Board), p. 22.
Drucker, Peter F. (1962), “The Economy's Dark Continent," Fortune, (April), p. 103, 265, 268, and 270

Fawcett, Stanley E. and Gregory M. Magnan (2002), "The Rhetoric and Reality of Supply Chain Integration," International Journal of Physical Distribution \& Logistics Management, v. 32, n. 5, p. 339-361.

Heskett, J. L.; N. A. Glaskowsky, Jr., and R. M. Ivie (1973), Business Logistics, 2. ed. (New York: The Ronald Press), p.14-21.
Heskett, J. L.; Robert M. Ivie, and Nicholas A. Glaskowsky, Jr. (1964), Business Logistics: Management of Physical Supply and Distribution (New York: The Ronald Press).

Kobayashi, I. (1973), "Management of Physical Distribution Cost," Proceedings of International Physical Distribution Conference, Tokyo, p. 9.

LaLonde, Bernard J. and Leslie M. Dawson (1969), "Pioneers in Distribution," Transportation and Distribution Management (June), p. 58-60.
LaLonde, Bernard J. and Paul H. Zinzer, (1976) Customer Service: Meaning and Measurement (Chicago: National Council of Physical Distribution Management).

Lambert, Douglas M.; Martha C. Cooper, and Janus D. Pagh (1998), "Supply Chain Management: Implementation and Research Opportunities," The International Journal of Logistics Management, v. 9, n. 2, p. 1-19.

Lewis, Howard T.; James W. Culliton, and Jack D. Steele (1956), The Role of Air Freight in Physical Distribution (Boston: Division of Research, Graduate School of Business Administration, Harvard University).

\section{Ronald H. Ballou}

Weatherhead School of Management

Case Western Reserve University

Cleveland, Ohio USA

(216) 368-3808

Ronald.Ballou@case.edu 